\title{
CARACTERIZAÇÃO MORFOANATOMICA E FISIOLÓGICA DE SEMENTES E PLÂNTULAS DE Jatropha curcas L. (Euphorbiaceae) ${ }^{1}$
}

Marta Bruno Loureiro², Clarissa Abreu Santos Teles ${ }^{3}$, Claúdio Cima Argolo Colares ${ }^{4}$, Bárbara Rosemar Nascimento de Araújo ${ }^{5}$, Luzimar Gonzaga Fernandez ${ }^{2}$ e Renato Delmondez de Castro ${ }^{2}$

\begin{abstract}
RESUMO - Jatropha curcas L., conhecida popularmente como pinhão-manso, é uma espécie encontrada em quase todas as regiões intertropicais do planeta. Possui sementes oleaginosas de importância medicinal e econômica, sendo apontada atualmente como promissora fonte de matéria-prima para a produção de biocombustíveis. Os objetivos deste trabalho consistiram em identificar as diferentes fases do processo de germinação, descrever e ilustrar a morfologia de sementes e plântulas de Jatropha curcas L. e os aspectos anatômicos das sementes, relacionando as mudanças que ocorrem nos tecidos durante as fases de embebição. Para a análise morfológica das sementes e plântulas, observaram-se os detalhes externos e internos. Para o estudo das fases de germinação, foi realizado um ensaio para avaliar o comportamento das sementes durante a embebição; para a análise anatômica, foram preparadas lâminas permanentes com cortes das sementes após 0, 4, 24 e 72 h de embebição. As sementes de Jatropha curcas L. são endospermáticas, elípticas e anátropas com tegumento glabro, possuindo poros e fissuras em sua superfície. Os cotilédones são foliáceos, com formato cordiforme e nervuras trinérvias. A germinação é do tipo fanerocotiledonar, epígea. Anatomicamente, as sementes são albuminosas, sendo o tegumento constituído de células parenquimáticas, vacuoladas e poligonais com feixes vasculares e células esclereficadas. O endosperma é composto por células poliédricas ricas em substâncias de reserva, principalmente lipídios. Durante as fases de germinação, observaram-se alterações no acúmulo de grânulos de amido presentes no endosperma, bem como mudanças na organização dos seus feixes vasculares.
\end{abstract}

Palavras-chave: Fanerocotiledonar; Embebição; Endosperma.

\section{MORPHOANATOMICAL CHARACTERIZATION AND PHYSIOLOGICAL OF SEEDS AND SEEDLINGS OF Jatropha curcas L. (Euphorbiaceae)}

\begin{abstract}
Jatropha curcas L. is a popularly known species found in almost all intertropical regions of the planet. The oil present in its seeds have medicinal properties and economic importance. The species is currently indicated as a promising source of raw material for biofuel production. Thus, the objectives of this study were to characterize morphologically seeds and seedlings of Jatropha curcas L., and to perform studies on tissue anatomy linking the seeds development to the seeds imbibition's stages. Internal and external details were found on the morphological analysis of the seeds and seedlings. Regarding the study of the germination stages, we conducted a test to evaluate the seeds' behavior during imbibition. For the anatomical analysis, permanent slides were prepared with section's tissues seeds after 0, 4, 24 and 72 hours of imbibition. The Jatropha curcas $L$. seeds are endospermatics, elliptical and anatropous with glabrous seed coat, presenting pores and fictions on its surface. The cotyledons are foliaceous, showing cordiform shape and trinervis ribbings. The germination is phanerocotylar epigeous. Anatomically the seeds are albuminous. The seed coat consists
\end{abstract}

\footnotetext{
${ }^{1}$ Recebido em 12.05.2009 aceito para publicação em 02.07.2013.

${ }^{2}$ Universidade Federal da Bahia, Instituto de Ciências da Saúde - Laboratório de Bioquímica, Biotecnologia e Bioprodutos. E-mail:<brunoloureiro70@gmail.com>,<luzimargonzaga@gmail.com>e <renatodel@gmail.com>.

${ }^{3}$ Mestre em Biotecnologia, Universidade Federal da Bahia, Salvador, BA, Brasil. E-mail: $<$ cllari@gmail.com>.

${ }^{4}$ Graduando em Ciências Biológicas, Universidade Federal da Bahia, Salvador, BA, Brasil. E-mail: <claudinho_biologia@yahoo.com.br>.

${ }^{5}$ União Metropolitana para o Desenvolvimento da Educação e Cultura. Laboratório de Histologia (UNIME). E-mail: <brosemar@ig.com.br>.
} 
of parenchymatic and polygons cells with vacuoles with vascular beams and sclerified cells. The endosperm is composed of polyhedral cells rich in reserve substances, mainly lipids. During the germination phases, alterations were observed in the reserve substances concentration of the endosperm, as well as changes in the organization of the vascular beams gifts.

Keywords: Phanerocotylar; Imbibitions; Endosperm.

\section{INTRODUÇÃO}

Jatropha curcas L., conhecida popularmente como pinhão-manso, é uma espécie da família Euphorbiaceae encontrada em quase todas as regiões intertropicais do planeta, tendo nas Américas do Sul e Central o centro de origem mais provável, apresentando características medicinais e podendo também ser utilizada na conservação do solo (CORTESÃO, 1956; PEIXOTO, 1973; BRASIL, 1985). No Brasil, vem sendo considerada pelo Governo Federal uma das oleaginosas mais promissoras das Regiões Sudeste, Centro-Oeste e Nordeste a ser utilizada na produção de biocombustíveis.

Os estudos relativos à morfologia de plântulas de espécies nativas têm recebido especial atenção nos últimos anos, destacando-se os com enfoque morfoanatômico que visam ampliar o conhecimento sobre determinada espécie vegetal e também o reconhecimento e identificação das espécies quando na fase de plântulas em estudos ecológicos (OLIVEIRA, 1993; ARAÚJO-NETO et al., 2002). Os aspectos morfoanatômicos de sementes são de fundamental importância nos estudos de paleobotânica, arqueologia, fitopatologia, na identificação de plantas e análise da qualidade de sementes para agricultura (OLIVEIRA, 1999; SILVA; PAOLI, 2000).

Durante o processo de germinação ocorre a reidratação dos tecidos e, consequentemente, a intensificação da respiração e de todas as outras atividades metabólicas, o que resulta no fornecimento de energia e nutrientes necessários para a retomada de crescimento do eixo embrionário (CARVALHO; NAKAGAWA, 2000). De acordo com Bewley e Black (1994), a embebição da maioria das sementes segue um padrão trifásico. Sendo o primeiro estádio um processo físico regulado pelo potencial matricial da semente, o segundo relacionado à preparação e ativação do metabolismo das sementes e o terceiro caracterizado pela retomada do crescimento do eixo embrionário.
As informações morfoanatômicas sobre as sementes de Jatropha curcas L. são ainda escassas, no entanto na literatura são encontrados estudos sobre a morfologia e anatomia de frutos e sementes de espécies da mesma família, a exemplo de Ricinus communis L. (SINGH, 1954), Manihot utilissima Pohl (TOLEDO, 1963), Croton floribundus Spreng e Croton urucurana Baill (PAOLI et al., 1995), Jatropha elliptica Mull. Arg. (AÑEZ et al., 2005), Manihot caerulescens Pohl, Manihot tripartita Mull Arg. (OLIVEIRA, 2007) e Cnidosculus juercifolius Paxe K. Hoffm. (SILVA et al., 2007), que podem ser utilizados como base para comparação dos estudos realizados com a espécie em questão.

Devido à importância econômica e ecológica dessa espécie, os objetivos deste trabalho foram identificar as diferentes fases ddo processo de germinação, bem como descrever e ilustrar a morfologia de sementes e plântulas de Jatropha curcas L. e os aspectos anatômicos das sementes, relacionando as mudanças que ocorrem nos tecidos durante as fases de embebição, de forma a descrever e caracterizar as sementes da espécie, o que dá, assim, subsídios para o desenvolvimento de estudos futuros.

\section{MATERIAL E MÉTODOS}

\subsection{Beneficiamento de sementes}

Os ensaios foram conduzidos no Laboratório de Estudos em Meio Ambiente da Universidade Católica do Salvador (LEMA/UCSal) e no Laboratório de Histologia da União Metropolitana para o Desenvolvimento da Educação e Cultura Ltda. (UNIME). As sementes de Jatropha curcas L. utilizadas foram cedidas pelo Banco de Germoplasma da Empresa Brasileira de Pesquisa Agropecuária/Centro de Pesquisa Agropecuário do Trópico Semiárido (EMBRAPA/ CPTSA). Após a coleta, as sementes foram beneficiadas, a fim de se descartarem os restos de frutos e outras impurezas. Em seguida, foram acondicionadas em sacos de polietileno e armazenadas em câmara climatizada, sob a temperatura média de $7^{\circ} \mathrm{C}$ e $50 \%$ de umidade relativa do ar até o início dos testes.

Revista Árvore, Viçosa-MG, v.37, n.6, p.1093-1101, 2013 


\subsection{Morfologia de sementes e plântulas de Jatropha curcas $\mathrm{L}$.}

Inicialmente, as sementes foram postas para embeber durante $24 \mathrm{~h}$ em água destilada, sendo posteriormente observados detalhes externos e internos da semente a olho nu e com o auxílio de microscópio estereoscópico binocular, registrando-se características como consistência, pilosidade, brilho e coloração. A metodologia e terminologia empregadas, assim como os parâmetros utilizados nas descrições, foram baseadas em Amorim et al. (1997), Barroso et al. (1999) e Cunha e Ferreira (2003).

As medidas biométricas foram tomadas com o auxílio de paquímetro digital Marathon com precisão de $0,01 \mathrm{~mm}$, em quatro repetições de 30 sementes. A fim de se determinar o tamanho médio das sementes, foram registrados o comprimento, a largura e a espessura.

Para condução do estudo morfológico das plântulas, as sementes passaram por desinfestação superficial com solução de hipoclorito de sódio $1 \%$, durante 3 min; em seguida, foram semeadas em copos plásticos descartáveis com capacidade para $500 \mathrm{~mL}$, contendo $125 \mathrm{~g}$ de vermiculita esterilizada. Esses recipientes foram dispostos em estantes de sala de crescimento sob a temperatura média de $25^{\circ} \mathrm{C}$ e fotoperíodo de $12 \mathrm{~h} / \mathrm{luz}$. As plântulas em diversos estádios de desenvolvimento foram caracterizadas e desenhadas, para a confecção das pranchas botânicas. A terminologia empregada e os parâmetros utilizados nas descrições basearam-se em Ducke (1965), Radford et al. (1974), Kuniyoshi (1983), Stern (1992), Oliveira (1993) e Raven et al. (1999).

\subsection{Curva de embebição de sementes de Jatropha curcas $\mathrm{L}$.}

O delineamento experimental utilizado foi o inteiramente casualizado com cinco repetições de 20 sementes por tratamento, sendo os tratamentos constituídos por 14 períodos de embebição $(0,6,12$, $18,24,36,48,60,72,84,96,108,120$ e 132 h). Para tal, as sementes foram dispostas em rolo de papel umedecido com água destilada em volume equivalente a três vezes o peso do substrato e incubadas em câmara tipo $\mathrm{BOD}$ à temperatura de $25 \pm 1{ }^{\circ} \mathrm{C}$, sob ausência de luz, de acordo com as recomendações de Brasil (1992). Após cada período de embebição, as sementes foram pesadas em balança de precisão para elaboração da curva de embebição, sendo registrado, além do peso, o número de sementes germinadas (emissão de raiz). Após a finalização do teste, os dados foram submetidos à análise de variância e de regressão, com o auxílio do Programa SISVAR (Versão 5.0, 1999-2003).

\subsection{Aspectos anatômicos de sementes de Jatropha curcas L. durante a embebição}

Com base nos resultados obtidos na curva de embebição de Jatropha curcas L., foram selecionados os períodos correspondentes às fases I, II e III do processo de embebição, a fim de relacionar as mudanças que ocorreram nos tecidos das sementes durante esse processo.

Para tal, inicialmente, as sementes foram postas para embeber em água destilada e retiradas após 0 , 4, 24 e 72 h de embebição. Em etapa posterior, foram

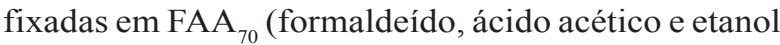
$70 \%$ ) durante sete dias, a fim de bloquear o metabolismo das células e, após esse processo, foram conservadas em etanol $70 \%$ até o início do emblocamento.

O procedimento para o emblocamento foi dividido em três etapas: desidratação, pré-infiltração e infiltração. O processo de desidratação consistiu numa sequência de trocas de solução de etanol e butanol de $70 \%$ até $100 \%$, seguido da imersão em butanol absoluto $(99,9 \%)$ por três vezes. A pré-infiltração foi realizada com butanol absoluto e óleo de parafina (1:1) e a infiltração com parafina, de acordo com a metodologia descrita em Kraus e Arduin (1997), modificada.

Os cortes anatômicos foram realizados com o auxílio de um micrótomo rotativo (LEICA RM2125RT) com 10 $\mu \mathrm{m}$ de espessura. Para a coloração dos tecidos, foram utilizados safranina $1 \%$ em etanol $70 \%$ e azul de alcian $1 \%$ em etanol $50 \%$, conforme metodologia descrita em Kraus e Arduin (1997), modificada. As lâminas foram montadas em bálsamo-do-canadá.

Foram também realizados testes histoquímicos para identificação de substâncias de reserva presentes nas células. Para tal, as amostras de sementes frescas foram cortadas transversalmente à mão livre e expostas a cloreto férrico para evidenciar a presença de compostos fenólicos e Sudam III para lipídios (KRAUS; ARDUIN, 1997).

A leitura das lâminas foi realizada com o auxílio de microscópio binocular (Nikon Eclipse E 600), e as imagens foram obtidas através de fotomicrografias feitas com câmara fotográfica (Nikon FDX-35) acoplada ao microscópio. 


\section{RESULTADOS E DISCUSSÃO}

\subsection{Morfologia de sementes e plântulas de Jatropha curcas L.}

Na Figura 1 são ilustrados os aspectos morfológicos da semente e do desenvolvimento da plântula de Jatropha curcas L. As sementes de pinhãomanso são endospermáticas, apresentam forma ovalada e dorso convexo, a rafe é bem visível e a carúncula possui formato cônico, coloração castanho-clara e encontra-se revestindo a região do hilo. Silva et al.
(2007), em trabalho com a espécie Cnidosculus juercifolius Pax \& K. Hoffm da família Euphorbiaceae, também verificaram uma rafe bem marcada longitudinalmente, como uma das características da semente. $\mathrm{O}$ tegumento possui coloração marrom-escura uniformemente distribuída, é glabro com textura porosa e apresenta fissuras em sua superfície. O endosperma possui coloração esbranquiçada, característica de outras espécies da mesma família, como Cnidosculus juercifolius (SILVA et al., 2007) e Jatropha elliptica Mull. Arg. (AÑEZ et al., 2005). Essa estrutura encontra-se

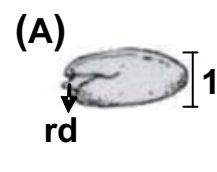

(B)

$1 \mathrm{~cm}$
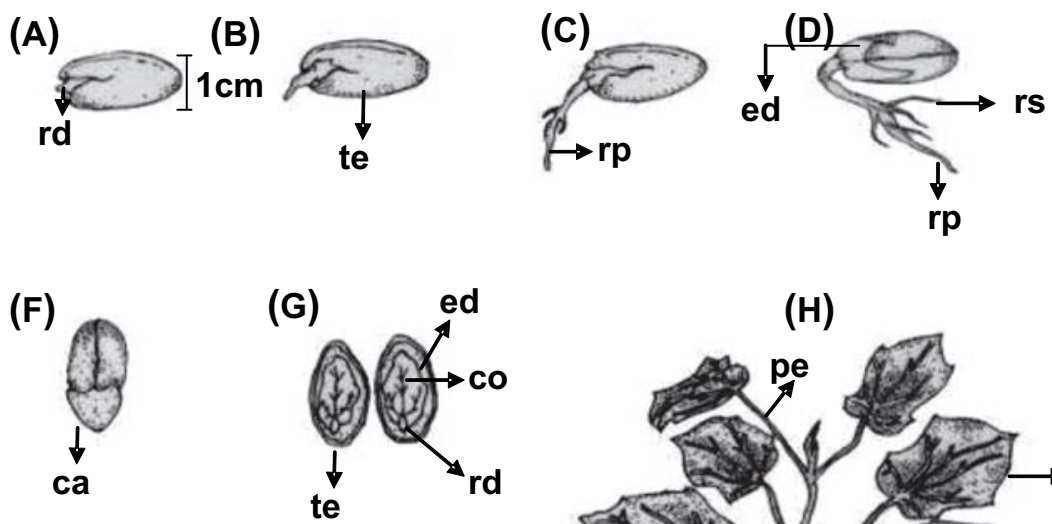

(H)
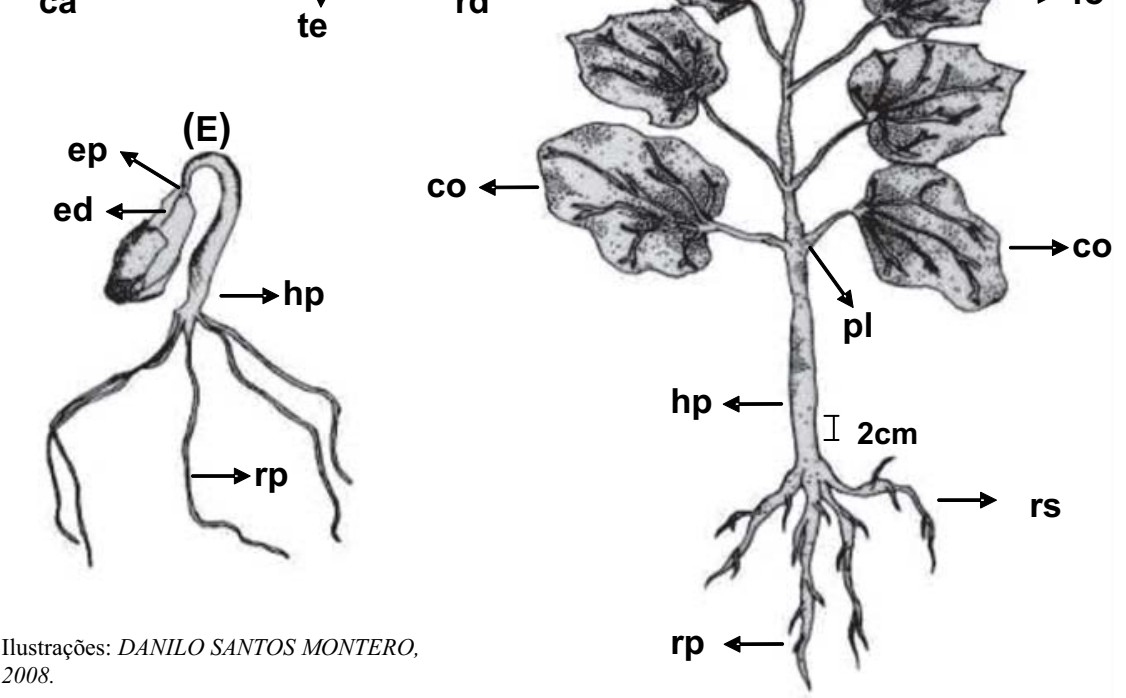

Figura 1 - Aspectos morfológicos de sementes e do desenvolvimento da plântula de Jatropha curcas L.: (A) - Protrusão da radícula; (B-D) - Aspectos do desenvolvimento da plântula; (F) Semente com carúncula; (G) - Aspecto interno da semente; $(\mathrm{H})$ - Corte longitudinal das sementes detalhando o endosperma, os cotilédones e o eixo embrionário; Ca-Carúncula; co - Cotilédone; ed - Endosperma; ep - Epicótilo; fl - Folha; h - Hipocótilo; te - Tegumento; pe - Pecíolo; pl - Pulvino; rp - Raiz primária; e rs - Raiz secundária.

Figure 1 - Morphological aspects of seeds and seedlings development of Jatropha curcas L.: (A) - Radicle protrusion; (B-D) - Seedling development aspects; (F) Seed with caruncle; (G) - Internal aspects of seed; (H) - Slitting detailing the endosperm, the cotyledons and the embryonic axis; Ca -Caruncle; co - Cotyledon; ed - Endosperm; pe - Epicotyl; fl-Leaf; $h$ - Hypocotyl; pe - Petiole; pl - Pulvinus; rp-Primary root; and rs - Secondary root

Revista Árvore, Viçosa-MG, v.37, n.6, p.1093-1101, 2013 
envolvendo totalmente o embrião, sendo este axial, espatulado, ou seja, reto com um eixo hipocótilo-radícula cilíndrico e curto; possui dois cotilédones foliáceos de coloração esbranquiçada e formato cordiforme, em que o ápice é atenuado e a base ampla, escavada e arredondada. Essas características também foram observadas por Paoli et al. (1995) em duas espécies da família Euphorbiaceae: Croton floribundus Spreng e Croton urucurana Baill. Os cotilédones possuem nervuras visíveis tanto na região adaxial quanto na abaxial, classificadas como trinérvias, sendo duas laterais que partem da base. Após 64 h de embebição, o eixo hipocótilo-radícula apresentou-se glabro, com textura lisa, sem nervação, coloração amarelo-esbranquiçada e tamanho aproximado de $0,3 \mathrm{~cm}$.

De acordo com a classificação de Raven et al. (1999), a espécie apresenta germinação do tipo epígea fanerocotiledonar, em que os cotilédones se expandem acima do nível do solo. Essa característica também foi verificada por Paoli et al. (1995) em Croton floribundus e Croton urucurana. Inicialmente, são formadas cinco raízes, sendo uma principal e quatro adventícias, que surgem da região do colo, sendo essa formação inicial idêntica ao desenvolvimento da espécie Jatropha elliptica, como descrito por Añez et al. (2005). A raiz principal é curta e glabra, de coloração esverdeada e formato cilíndrico. Desenvolve-se rapidamente, e durante esse processo se pode verificar que a base e região do colo se tornam mais espessas, afunilando-se em direção à coifa. As raízes laterais possuem o mesmo padrão de desenvolvimento da raiz principal, sendo menos espessas. O hipocótilo desenvolve-se simultaneamente com as raízes; é glabro, de coloração esverdeada e possui diâmetro maior na base, próximo ao colo, que vai diminuindo próximo à inserção dos cotilédones. Silva et al. (2007) verificaram que o hipocótilo de Cnidosculus juercifolius (Euphorbiaceae) tem características semelhantes às de J. curcas, como coloração verde, aspecto ampuliforme, de textura lisa, brilhoso, engrossado e latescente.

\subsection{Curva de embebição de sementes de Jatropha curcas $\mathbf{L}$.}

Conforme resultados da curva de embebição (Figura 2), pode-se verificar que as sementes da espécie estudada apresentaram padrão trifásico de embebição, de acordo com modelo proposto por Bewley e Black (1994). A fase I foi verificada entre os períodos de 0

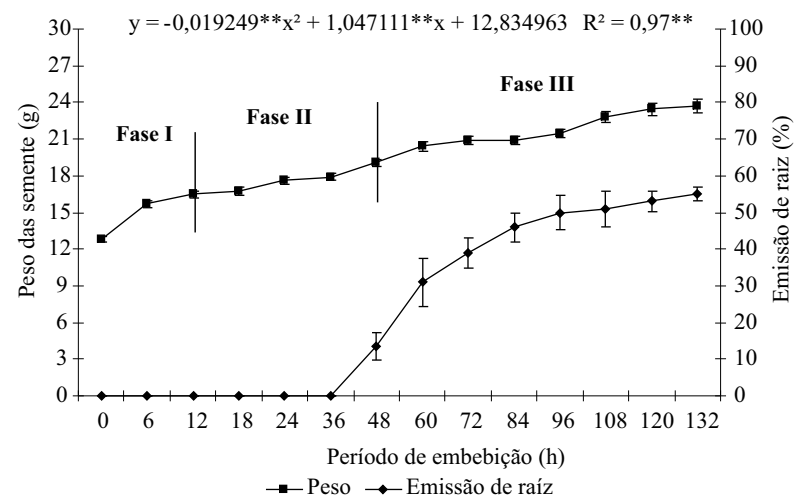

Figura 2 - Curva de embebição em sementes de Jatropha curcas L.

Figure 2 - Imbibition curve of Jatrhopha curcas L. seeds.

a 12 h, caracterizada pela rápida absorção de água e aumento do peso das sementes. A fase II foi registrada entre 12 e 48 h de embebição, que, de acordo Bewley e Black (1994), é a fase em que a absorção de água se dá em níveis baixos, sendo o momento em que a semente adquire condições físico-químicas para reativação de seu metabolismo, enquanto na fase III, em que ocorre a protrusão da raiz primária, foi verificada a partir das $48 \mathrm{~h}$ de embebição.

Dantas et al. (2007) também verificaram um padrão trifásico na curva de germinação de Jatropha curcas L., sendo a fase I completada em $48 \mathrm{~h}$, a fase II teve duração de $40 \mathrm{~h}$ e a fase III foi iniciada após $88 \mathrm{~h}$ de embebição. Essa diferença verificada entre sementes da mesma espécie pode ser atribuída às condições de condução do experimento, à procedência do lote e ao vigor, podendo este ser afetado durante a maturação, secagem e armazenamento das sementes.

Souza et al. (2005), em estudos de vigor de sementes de Tabebuia serratifolia (Vahl.) Nich. utilizando dois tipos de acondicionamento (embalagens de papel e polietileno) e diferentes ambientes de armazenamento (câmara, laboratório e geladeira), concluíram que ocorreu diminuição no vigor com o decorrer do tempo, mas que as sementes armazenadas em ambiente de geladeira ( $7{ }^{\circ} \mathrm{C}$ e $54 \%$ UR) apresentaram os maiores índices de vigor em relação aos outros tratamentos. Neste trabalho, as sementes de Jatropha curcas L. foram armazenadas em câmara climatizada $\left(7^{\circ} \mathrm{C}\right.$ e $50 \%$ UR), podendo ser esta uma das possíveis causas da diferença verificada entre os resultados deste estudo e o conduzido por Dantas et al. (2007).

Revista Árvore, Viçosa-MG, v.37, n.6, p.1093-1101, 2013 


\subsection{Aspectos anatômicos de sementes de Jatropha curcas L. durante a embebição}

As sementes de Jatropha curcas L. são bitegumentadas e exotégmicas, ou seja, o exotégmen representa a camada mecânica do tegumento da semente madura (APEZZATO-DA-GLÓRIA; CARMELLOGUERREIRO, 2003). São albuminosas, elípticas e anátropas. Oliveira (2007), em seu estudo com duas espécies da família Euphorbiaceae, gênero Manihot, M. caerulescens Pohl. e M. tripartita Mull. Arg., também observou tais características para essas sementes.

O tegumento das sementes de J. curcas é constituído externamente pela testa e internamente pelo tégmen. A testa apresenta três camadas distintas, sendo a primeira e mais externa a exotesta, formada por células alongadas; a segunda, a mesotesta com um estrato de células parenquimáticas, vacuoladas e poligonais e apresenta feixes vasculares; e a terceira e mais interna, a endotesta, composta por células achatadas. O tégmen apresenta o exotégmen com uma camada com células alongadas, justapostas e esclereficadas e o mesotégmen formado por uma fina camada de células achatadas (Figura 3A-C).

Paoli (1997), em estudos da anatomia de sementes de Lophantera lactescens Ducke (Malpighiaceae), também verificou diferenciação do tégmen em exo, meso e endotégmen, sendo o exotégmen formado por fibras lignificadas, que assim como em Jatropha curcas L. é a camada mecânica do tegumento.

De acordo com Córner (1976), em alguns gêneros de Euphorbiaceae, como Acthephila, Baccaurea, Drypetes e Phyllanthus, o exotégmen pode ser constituído por um estrato de células longitudinais esclerificadas, uma camada de fibras, esclereídes cuboides ou uma pequena paliçada.

Toledo (1963), em seu trabalho com sementes de mandioca (Manihot utilissima Poh1.), descreveu a estrutura do tegumento com semelhanças à semente de Jatropha curcas L.

Singh (1954) verificou que em sementes de Ricinus communis o tegumento externo é representado pela epiderme externa, constituída por células alongadas tangencialmente, a epiderme interna é constituída de células colunares e camadas de células parenquimáticas comprimidas, e a epiderme externa do tegumento interno apresenta células semelhantes à paliçada e esclerificadas.
Tais descrições do tegumento se assemelham às sementes de Jatropha curcas L., sendo características presentes na família Euphorbiaceae.

O tecido endospermático está localizado em seguida ao mesotégmen. O endosperma das sementes de Jatropha curcas L. é composto por células poliédricas ricas em substâncias de reserva, principalmente lipídios (Figura 3D-F). Esses resultados concordam com os verificados por outros autores em espécies da mesma família. Oliveira (2007), estudando os aspectos anatômicos de sementes de Manihot caerulescens Pohl. e Manihot tripartita Mull Arg., observou que o endosperma destas apresenta células com paredes delgadas, que acumulam ampla reserva de origem lipídica e proteica. Também em sementes de Manihot utilissima Pohl., o endosperma é composto de células poliédricas ricas em substâncias de reserva, principalmente óleo ( TOLEDO, 1963).

Na Figura 3D-F está representado o tecido parenquimático do endosperma nas fases I e II do processo de embebição. Pode-se verificar que houve diminuição das gotículas de lipídeo neste tecido, conforme a mudança de fases, tornando-se as células mais túrgidas e vazias. Suda e Giorgini (2000) verificaram que a degradação dos lipídios no endosperma de Euphorbia heterophylla L. (Euphorbiaceae) se iniciou logo após as primeiras horas de embebição, sendo completada entre 72 e $96 \mathrm{~h}$, período esse correspondente à fase III desse processo, quando ocorreu a germinação. Uma justificativa para diminuição da concentração das substâncias de reserva é a translocação destas para o eixo hipocótilo-radícula, com a finalidade de fornecer energia para o alongamento e crescimento celular durante a germinação das sementes.

Os cotilédones são envoltos pelo endosperma e apresentam aspecto foliáceo (Figura 3G). Na Figura 3H, observa-se a divisão entre os dois cotilédones.

$\mathrm{Na}$ Figura 3I estão representados os feixes vasculares encontrados na radícula e parte do endosperma, no período de $24 \mathrm{~h}$, correspondente à fase II do processo de embebição. No período de $72 \mathrm{~h}$, observa-se a radícula com alongamento dos feixes, além de expansão e crescimento sobre o tecido, caracterizando a fase III, como pode ser verificado na Figura 3J.

A Figura 3L apresenta fotomicrografia do período de $4 \mathrm{~h}$ de embebição, em que se pode verificar parte do endosperma rodeado por feixes vasculares e células em fase de diferenciação. 

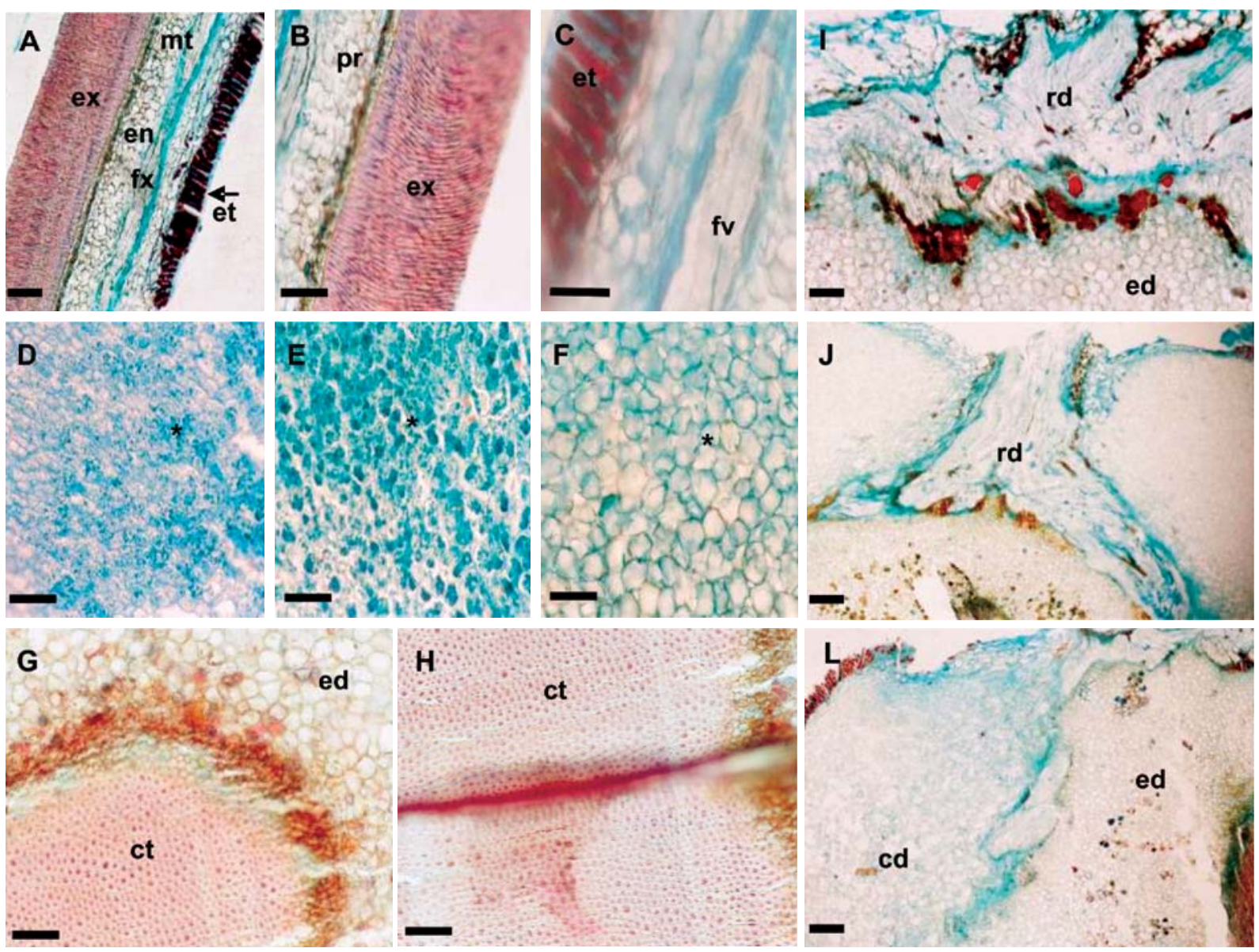

Figura 3 - Anatomia de sementes de Jatropha curcas L. durante fases da germinação: A - Estruturas do tegumento da semente $(0,92 \mu \mathrm{m}) ; \mathrm{B}-$ Detalhe do exotégmen $(0,45 \mu \mathrm{m}) ; \mathrm{C}-$ Tegumento externo $(0,22 \mu \mathrm{m})$; D-F - Tecido endosperma em diferentes fases de germinação $(0,4$ e $24 \mathrm{~h}$, respectivamente) $(0,45 \mu \mathrm{m}) ; \mathrm{G}$ - Tecidos, endosperma e cotilédone $(0,45 \mu \mathrm{m}) ; \mathrm{H}$ - Divisão entre os cotilédones $(0,45 \mu \mathrm{m}) ; \mathrm{I}$ - Feixes da radícula na fase II $(0,92 \mu \mathrm{m}) ; \mathrm{J}$ - Radícula na fase III, mostrando alongamento das células $(0,92 \mu \mathrm{m}) ; \mathrm{L}$ - Endosperma com células diferenciadas $(0,92 \mu \mathrm{m})$; et - Exotesta; mt - Mesotesta; en - Endotesta; fx - Feixe vascular; ex - Exotégmen; pr - Parênquima; ed Endosperma; ct - Cotilédone; e rd - Radícula.

Figure 3 - Anatomy of Jatropha curcas L. seeds during germination stages: A - Seed coat structures (0.92 nm); B - Details of the exotegmen $(0.45 \mathrm{~nm})$; C - External seed coat $(0.22 \mathrm{~nm}) ; D F$ - Endosperm tissue at different stages of germination (0, 4 and 24 hours, respectively) $(0.45 \mathrm{~nm}) ; G$ - Endosperm and cotyledons tissue $(0.45 \mathrm{~nm}) ; \mathrm{H}$ - Division between the cotyledons $(0.45 \mathrm{~nm})$; I - Radicle beams in phase II of germination (0.92 $\mathrm{nm})$; $\mathrm{J}$ - Radicle in phase III, showing cells elongation (0.92 nm); L - Endosperm with different cells (0.92 nm); et - Exotesta; mt - Mesotesta; in - Endotesta; $f x$-Vascular bundle; ex - Exotegmen; pr - Parenchyma; ed - Endosperm; $c t$ - Cotyledon; and rd-Radicle.

Dessa forma, pode-se concluir que as sementes de Jatropha curcas L. são endospermáticas, com germinação do tipo faneroepígea, bitegumentadas e exotégmicas, sendo o tégmen dividido em três camadas. As células parenquimáticas apresentam lipídios como principal substância de reserva dessas sementes.

\section{AGRADECIMENTOS}

Ao CNPq, pela concessão das bolsas Prodoc e Iniciação Científica; à FAPESB, pela viabilização financeira para condução deste trabalho; e à Empresa Brasileira de Pesquisa Agropecuária - Trópico Semiárido, pelo fornecimento das sementes da espécie estudada.

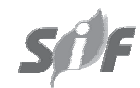

Revista Árvore, Viçosa-MG, v.37, n.6, p.1093-1101, 2013 


\section{REFERÊNCIAS}

AMORIM, I. L.; DADIVE, A. C.; CHAVES, M. M.F. Morfologia do fruto e da semente, e germinação da semente de Trema micrantha (L.) Revista Cerne, v.3, n.1, p.129-142, 1997.

AÑEZ, L. M. M. et al. Caracterização morfológica dos frutos, das sementes e do desenvolvimento das plântulas de Jatropha elliptica Müll. Arg. (Euphorbiaceae). Revista Brasileira de Botânica, v.28, n.3, p.563-568, 2005.

APEZZATO-DA-GLÓRIA, B.; CARMELLOGUERREIRO, S. M. Anatomia vegetal. Viçosa, MG: Universidade Federal de Viçosa, 2003. p.406-407.

ARAÚJO NETO, J. C. et al. Caracterização morfológica de frutos e sementes e desenvolvimento pós-seminal de monjoleiro (Acacia polyphylla DC.). Revista Brasileira de Sementes, v.24, n.1, p.203-211, 2002.

BARROSO, G. M. et al. Frutos e sementes: morfologia aplicada à sistemática de dicotiledôneas. Viçosa, MG: Universidade Federal de Viçosa, 1999. p.443.

BEWLEY, J. D.; BLACK, M. Seeds: Physiology of development and germination. 2.ed. New York: Plenum Press, 1994. 445p.

BRASIL. Ministério da Indústria e do Comércio. Secretaria de Tecnologia Industrial. Produção de combustíveis líquidos a partir de óleos vegetais. Brasília: STI/CIT, 1985. 364p.

BRASIL. Ministério da Agricultura e Reforma Agrária. Regras para análise de sementes. Brasília: SNDA/DNDV/CLAV, 1992.365p.

CARVALHO, N. M.; NAKAGAWA, J. Sementes: ciência, tecnologia e produção. Jaboticabal: Funep, 2000. 588p.

CORNER, E. J. H. The seeds of dicotyledons. Cambridge: University Press, 1976. $311 \mathrm{p}$

CORTE, V. B. et al. Histochemical aspects of reserves mobilization of Caesalpinia peltophoroides (Leguminosae) seeds during germination and seedlings early growth. Revista Árvore, v.32, n.4, p.641-650, 2008.
CORTESÃO, M. Culturas tropicais: plantas oleaginosas. Lisboa: Clássica, 1956. 231 p.

DANTAS, B. et al. Tecnologia de sementes de Pinhão Manso (Jatropha curcas): Avaliações iniciais da qualidade fisiológica. In: CONGRESSO DA REDE BRASILEIRA DE TECNOLOGIA DO BIODIESEL. Arquivos eletrônicos, publicações, Agricultura, 2., 2007, Brasília. Anais... Brasília: 2007. Disponível em: <http:// www.biodiesel.gov.br/rede_arquivos/ agriculturaII.htm> Acesso e-m: 27 mar. 2009.

DUCKE, J. A. Keys for the identification of seedlings of some species in eight forest types in Puerto Rico. Annals of Missouri

Botanical Garden, v.52, n.3, p.314-350, 1965.

ESAU, K. Anatomia das plantas com sementes. 15.ed. São Paulo: Edgar Blucher, 2000.293p.

KRAUS, E. J.; ARDUIN, M. Manual básico de métodos em morfologia vegetal. Rio de Janeiro: Edur, 1997. 198p.

KUNIYOSHI, Y. S. Morfologia da semente e da germinação de 25 espécies arbóreas de uma floresta de Araucária. 1983. 233f. Dissertação (Mestrado em Engenharia Florestal) - Universidade Federal do Paraná, Curitiba, 1983.

OLIVEIRA, E. C. Morfologia de plântulas florestais. In: AGUIAR, I. B.; PIÑA-RODRIGUES, F. C. M.; FIGLIOLIA, M. B. Sementes florestais tropicais. Brasília: ABRATES, 1993. p.175-214.

OLIVEIRA, D. M. T. Morfo-anatomia do embrião de leguminosas arbóreas nativas. Revista Brasileira de Botânica, v.22, n.3, p.413-147, 1999.

OLIVEIRA, J. H. G. Morfologia, anatomia e desenvolvimento do fruto e semente de Manihot caerulescens Pohl. e M. tripartita Mull. Arg. (Euphorbiaceae). 2007. 74f. Dissertação (Mestrado em Botânica) Universidade de São Paulo, 2007.

PAOLI, A. A. S.; FREITAS, L.; BARBOSA, J. M. Caracterização morfológica dos frutos, sementes e plântulas de Croton floribundus spreng. e de Croton urucurana Baill. (euphorbiaceae).

Revista Brasileira de Sementes, v.17, n.1, p.57-68, 1995. 
PAOLI, A. A. S. Morfo-anatomia de frutos e sementes de Lophantera lactescens Ducke (Malpighiaceae). Revista Brasileira de Sementes, v.19, n.2, p.237-243, 1997.

PEIXOTO, A. R. Plantas oleaginosas arbóreas. São Paulo: Nobel, 1973. 284p.

RADFORD, A. E. et al. Vascular plants systematics. New York: Harper and Row, 1974. 877p.

RAVEN, P. H.; EVERT, R. F.; EICHHORN, S. E. Biology of plants. 6.ed. New York: W. H. Freeman and Company, 1999.

SILVA, L. L.; PAOLI, A. A. S. Caracterização morfoanatômica da semente de Zanthoxilum rhoifolium Lam. (Rutaceae). Revista Brasileira de Sementes, v.22, n.2, p.250-256, 2000.

SILVA, L. M. M.; AGUIAR, I. B.; TERTULIANO, S. S. X. Morfologia de frutos, sementes e plântulas de Cnidosculus juercifolius Pax \& K. Hoffm (Euphorbiaceae). Revista de Biologia e Ciências da Terra, v.7, n.2, p.1519-5228, 2007.
SINGH, B. Studies on the structure and development of seeds of curcubitaceae. Phytomorphology, v.3, p.224-239, 1953.

SOUZA, V. C.; BRUNO, R. L. A.; ANDRADE, L. A. Vigor de sementes armazenadas de Ipê-amarelo Tabebuia serratifolia (Vahl.) Nich. Revista Árvore, v.29, n.6, p.833-841, 2005.

SUDA, C. N. K.; GIORGINI, J. F. Composição e mobilização de reserva da semente de Euphorbia heterophylla durante a germinação e desenvolvimento inicial da plântula. Revista Brasileira de Fiologia Vegetal, v.12, n.3, p.226-245, 2000.

STERN, W. T. Botanical latin. History, grammar, syntax,terminology and vocabulary. New York: Hafner Publishing Company, 1992. 566 .

TOLEDO, A. P. Anatomia e desenvolvimento ontogenético do fruto e da semente de mandioca. Bragantia, v.22, Numero único, p.521-526, 1963. 
